\title{
VERSLAG VAN DE CONSERVATOR OVER HET JAAR 2006
}

\section{Aanwinsten}

Shuko, hangrolschildering, vlotten op de rivier, inkt en kleur op zijde, $130 \mathrm{x}$ $50 \mathrm{~cm}$., Japan, 1918, AK-RAK-2006-1

Masker van prinses Srikandi, hout, Java, $19^{e}$ eeuw, in bruikleen sinds 1962 , AK-RAK-2006-2

Masker van Ombakarna, hout, Java, $19^{\mathrm{e}}$ eeuw, in bruikleen sinds 1962 , AK-RAK-2006-3

Beeld van Europese tribuutbrenger, ivoor met sporen van polychromie, h. $15,8 \mathrm{~cm}$., China, midden $18^{\mathrm{e}}$ eeuw, AK-RAK-2006-4

Vork, zilver, 1. $21,5 \mathrm{~cm}$., China, ca. 1850, AK-RAK-2006-5-A

Lepel, zilver, 1. $19 \mathrm{~cm}$., China, ca. 1850, AK-RAK-2006-5-B

\section{Bruiklenen aan tentoonstellingen}

'prenten op porselein' in CODA Apeldoorn, tot 19 maart 2006, een groep Chine de commande-porselein

'Mysterieus Celadon: groen geglazuurde keramiek uit Azië', Princessehof Leeuwarden, 19 februari - 17 septemer 2006, een groep celadon keramiek 'Willem Kalf, een zeventiende-eeuwse meester herontdekt', Museum Boijmans van Beuningen Rotterdam, 25 november 2006 - 18 februari 2007 (vervolgens naar Suermondt-Ludwig-Museum Aken), een kom met biscuit-figuren (AK-MAK-563)

\section{Opstelling CODA}

In december werd een nieuwe opstelling in CODA Apeldoorn gerealiseerd met als thema thee. Japanse theekeramiek en porselein en zilver van de Nederlandse theetafel zijn zij aan zij tentoongesteld.

\section{Restauraties}

stapeldoos van Chinees lakwerk, 1795, AK-RAK-2005-2. Door Carolien van Es (Snoek en Van Es, Leidschendam)

12 voorwerpen Japans lakwerk (in het kader van een langlopend project voor de conservering van de lakwerkcollectie) AK-MAK-140, AK-MAK-142, AK-MAK-144, AK-MAK-585, AK-MAK-586, AK-MAK-588, AK-MAK-702, AK-MAK-870, AK-MAK-871, AK-MAK-881, AK-MAK-882, AK-MAK-1211. Eveneens door Carolien van Es.

\section{Onderzoek en documentatie}

Agnita van 't Klooster, conservator islamitische keramiek in Museum Princessehof Leeuwarden, heeft de collectie Midden-Oosten keramiek bestudeerd en toeschrijvingen nagekeken. Een eerste resultaat van haar werk is gepubliceerd in Vormen uit Vuur 195 (2006/2). 'De collectie Oosterbaan: 40:36PM Lugt; Iraanse keramiek van gepassioneerde verzamelaars'. 
Afbeelding Stapeldoos uit de collectie A.E. van Braam Houckgeest, hout met zwarte lak en goudlak, h. 45,5 cm., China, 1795, gerestaureerd in 2006

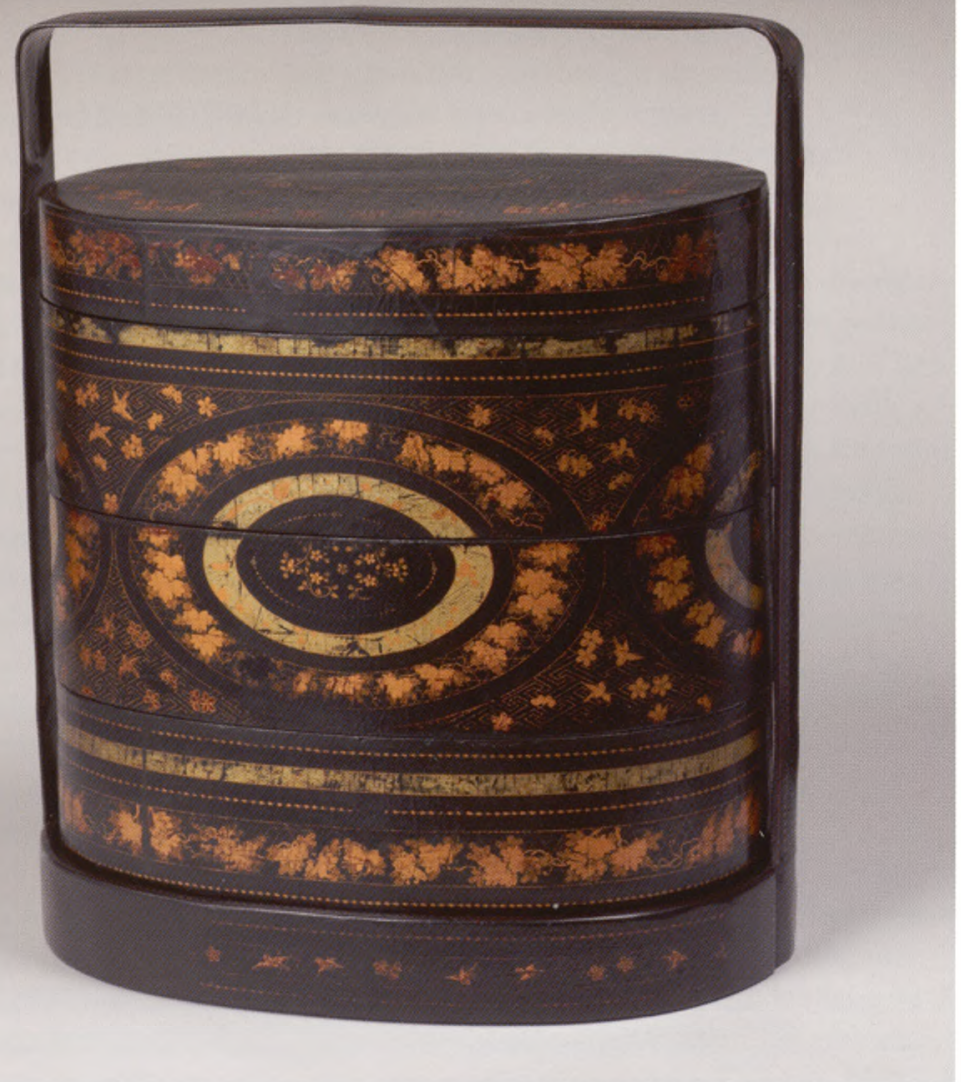

\section{Publicaties van medewerkers Rijksmuseum afdeling Aziatische Kunst}

Menno Fitski

[met Eveline Kamstra] 'Een verzameling van opiumpijpen', Aziatische Kunst 36/1 (2006), 1, pp. 3-8

'Een Chinees beeld van een zittende Lohan', Bulletin van het Rijksmuseum 54/1 (2006), pp. 3-7

Pauline Lunsingh Scheurleer

'De Vlaggen van het VOC-gezantschap naar de Mughal-keizer in 1689',

Vlaggentijdschrift Vexilla Nostra 248, pp. 10-15

'Een ivoren paneeltje', Aziatische Kunst 36/2 (2006), pp. 14-20

'Map of Hindustan with portrait of the Mughal Emperor Jahangir' en

'Audience of the Mughal Emperor Shah Jahan', in: Peter van der Krogt en Erlend de Groot, The Atlas Bleau - Van der Hem of the Austrian National Library. Deel 5, 't Goy-Houten, pp. 265 en 326

\section{Jan van Campen}

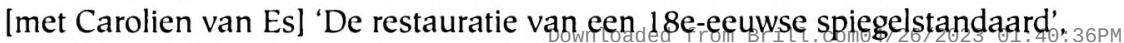




\section{Voordrachten en lezingen}

\section{Menno Fitski}

'Introductie tot de afdeling Aziatische Kunst van het Rijksmuseum', Coda Museum, Apeldoorn, 25 maart

'Sherds of evidence: the study and collecting of Japanese porcelain by Oliver Impey', Ashmolean Museum, Oxford, 31 mei (symposium in Memory of Dr. Oliver Impey (1936-2005))

'De Japanse theeceremonie', Van Gogh Museum, 9 juli en 10 september 'De inrichting van het Paviljoen voor Aziatische kunst', Rijksmuseum,

13 september en 4 december (informatiebijeenkomst voor vakgenoten) 'Het Aziatisch paviljoen', Rijksmuseum, 24 september (zondagmiddaglezing) 'Het Paviljoen voor Aziatische kunst van het Nieuwe Rijksmuseum',

Nederlands Genootschap voor Japanse Studiën, Leiden, 15 december

\section{Pauline Lunsingh Scheurleer}

'Grepen uit de Oud-Javaanse Kunstgeschiedenis', Velpse Kunstclub, Velp, 24 februari

'Oud-Javaanse beeldhouwkunst en goudschatten', Coda Museum, Apeldoorn, 2 maart

'Goudschatten uit Java', Nieuwe Kerk, Amsterdam, 18 maart (t.g.v. de tentoonstelling 'Indonesia: de ontdekking van het verleden')

'Collecting Javanese Antiquities: Appropriation of a newly discovered Asian Civilization', Nieuwe Kerk, Amsterdam, 24 maart (seminar 'Collecting Cultural Heritage in Indonesia')

'Boeddhistische kunst van Indonesië', Universiteit van Leiden, 27 maart (collegereeks Boeddhistische kunst van Azië)

'Central and East Javanese Shivaite Sculpture' en 'Gold Treasures from Indonesia', Nieuwe Kerk, Amsterdam, 7 april (British Museum Asian Art Course)

\section{Externe activiteiten}

\section{Menno Fitski}

vice-voorzitter Vereniging voor Japanse Kunst

voorzitter Heinz Kaempfer Fund

secretaris Nederlands Genootschap voor Japanse Studiën

bestuurslid Hulsewé-Wazniewski Stichting

redactielid Aziatische Kunst

\section{Pauline Lunsingh Scheurleer}

consultant inrichting schatkamer met Indo-Javaans goud in nieuwe gebouw van nationaal Museum van Indonesië in Jakarta (onderdeel samenwerkingsproject tussen dit museum en het Rijksmuseum voor Volkenkunde te Leiden)

adviseur Vereniging van Vrienden van Instituut Kern te Leiden i.v.m. twee

Balinese schilderingen op doek gebruikt bij de crematie van de stedehouder Jlantik in 1916

Jan van Campen redactielid Vormen uit Vuur redactielid Aziatische Kunst 